\title{
THE GROWTH PHASE AND ITS EFFECT ON BUD PROLIFERATION AND GROWTH OF IN VITRO CULTURE OF HEVEA BRASILIENSIS
}

\author{
P. SENEVIRATNE and G.A.S. WIJESEKARA \\ Department of Plant Science, Rubber Research Institute of Sri Lanka, Dartonfield, \\ Agalawatta.
}

(Received: 5 May 1994 ; accepted: 2 December 1994)

\begin{abstract}
The physiological growth state of the plant when explants are harvested, is the most important factor in micropropagation of Hevea brasiliensis. Nodal explants, removed from 4-5y old trees behaved similarly to those harvested from few weeks old embryo cultured plants. But, the explants from clonal trees which are mature were not as responsive as juvenile materials at any age of growth. The differences in behaviour of the two types of shoots included the culture establishment due to the difficulties in surface sterilization and phenolic browning associated with clonal materials. However, nodal explants were better than shoot apices for axillary shoot growth of both clonal and juvenile materials of Hevea sp. Manipulation of the stock plants is more important than the culture medium or technique when working with clonal materials of Hevea.
\end{abstract}

Key words: Hevea brasiliensis, micropropagation.

\section{INTRODUCTION}

The conventional method of propagation of Hevea brasiliensis is by grafting buds from selected clones onto unselected seedling rootstocks. Rooted cuttings are not recommended for Hevea due to the absence of a proper root system on cuttings and also because of the difficulty in inducing even a fibrous root system. Unpredictable root stock-scion interactions cause considerable variation in the growth and the yield of plants of any clone. A satisfactory method of propagation. is therefore not available for Hevea to produce true-to-type plants. As a result, Hevea has not yielded its maximum potential in plantations. In vitro propagation or micropropagation is a promising technique to solve this problem.

The capacity to propagate vegetatively is strongly associated with juvenility though there is no clearly defined transition from the juvenile to mature phase in most plants. Maturation is highly correlated with flowering and the most general characteristic of juvenility is the inability to flower. It is certainly not a single on/off event restricted to flowering, but an accumulation of events with time such as changes in rooting ability and quality, growth rate, plagiotropism, leaf morphology, phylotaninns, anthocyanin content, hairiness, leaf retention, branch angle, thorniness etc. ${ }^{1}$ Perennial trees can have juvenile periods that last 6-15 years. For rubber, from the seedling up to $4 \mathrm{y}$ old tree is considered as juvenile, age 6 as entering into mature phase and age 5 as the transitional period. ${ }^{2}$ Maturation of trees has been defined as the development process including changes in morphological and physiological characteristics leading to the

Abbreviations: $\mathrm{BAP}=6-\mathrm{Benzylaminopurine}, \mathrm{NAA}=$ Naphthalene acetic acid . 
reproductive state: An important mature characteristic of cells or tissues is that they have lost the capacity for adventitious organ or embryo formation. Meristematic apices undergo changes when the plants mature and therefore, tissues derived from these apices behave differently in young and old plants. . $^{3,4}$ It is believed that the juvenility is an unstable state which exists in the meristem and which proceeds through a series of steps to a relatively stable state which is characteristic of the adult meristem. Changes occur in buds with time, so that they acquire a certain individuality persisting even after a bud is separated from the plant and these changes are not easily disturbed. ${ }^{5}$ In the application of tissue culture to trees, obtaining relatively juvenile material from mature plants is very desirable because, on one hand, they are more easy to handle in tissue culture systems and on the other hand, these tissues contain higher regeneration capacity. Though the immediate need for Hevea is the clonal propagation to produce true-to-type plants, to realize the known capacity of the species, considerable research has been done on somatic embryogenesis ${ }^{6-8}$ due to the fact that the tissues that retain at least some degree of regeneration can be used only for somatic embryogenesis. The technique of axillary shoot proliferation has been tried for micropropagation of Hevea, but the success has been limited to juvenile materials. Rooting of shoot tips ${ }^{8}$ and shoot multiplication ${ }^{9}$ have been reported for embryo cultured plants. Axillary shoot proliferation of nodal cuttings has been reported with various rates of multiplication ${ }^{8,11}$ after using combinations of different growth regulators. Shoot doubling time of $28 \mathrm{~d}$ has been reported from about $2 y$ old glass house-grown explants. ${ }^{10}$ No sustainable shoot proliferation has so far been reported for mature origin shoot materials though there are reports of primary axillary bud elongation. ${ }^{10,11}$ We report here the different behavior of juvenile and mature Hevea shoot materials in tissue culture . systems, and in particular, problems encountered in the technique of enhanced release of axillary buds.

\section{METHODS AND MATERIALS}

Plant material : Shoot tips and nodes from juvenile and mature plants were used. Juvenile plant material was harvested mainly from glasshouse-grown seedlings and also from embryo cultured plants. The plants were $<4 y$ old. Mature shoots were harvested from field-grown trees and also from budded stumps of clones RRIC 100, RRIC 102,RRIC 110, RRIC 117 and RRIC 121 grown in polyethylene sleeves. These plants were kept in the glasshouse and the terminal shoots were pruned regularly in order to enhance the development of new lateral shoots. The age of the plants varied from $6 \mathrm{~m}$ to $2 \mathrm{y}$.

Media : Murashige and Skoog medium (Flow laboratories,England) was used for cultures. All other chemicals were analar grade from BDH, England. Hormones were from Sigma, U.S.A. Vitamin stocks were stored frozen and hormones at $4^{\circ} \mathrm{C}$. Hormones were prepared fresh every 4 weeks. Sucrose was used at $20 \mathrm{~g} / \mathrm{l}$ and PVP at $100 \mathrm{mg} / \mathrm{l}$ unless otherwise stated. $\mathrm{pH}$ of the medium was adjusted to 5.7 before adding agar at $6 \mathrm{~g} /$. Three combinations of kinetin, BAP \& NAA were tried along with the control medium containing no hormones. 
The hormone combinations of the four media were as follows; (concentrations in $\mathrm{mg} / \mathrm{l})$.
S-0
S-1
S-2
S-3

Kinetin

2

BAP

0

2

7.5

0

NAA

0

0.2

3.75

5

0.2

0.2

Sterilization : Juvenile shoots were sterilized with $70 \%$ ethanol for $1 \mathrm{~min}$ followed by $15 \% \mathrm{NaOCl}$ for 10 mins. For mature materials $0.2 \% \mathrm{HgCl}_{2}$ was used instead of $\mathrm{NaOCl}$. Explants were shaken throughout and washed several times with sterilized water. Media, water and instruments were sterilized in an autoclave at $121^{\circ} \mathrm{C}$ under $15 \mathrm{lb} /$ inch $^{2}$ for 20 minutes.

Culturing and incubation: After sterilization of shoots, pieces about $1 \mathrm{~cm}$ from the bases of shoot tips and two such pieces from either side of the nodes were trimmed prior to placing them on media in petri dishes. Cultures were incubated at $25 \pm 2^{\circ} \mathrm{C}$ under $16 \mathrm{~h}$ photoperiod at irradiance of about $100 \mu \mathrm{E} / \mathrm{m}^{-2}$ of $\mathrm{s}^{-1}$ supplied by cool white fluorescent tubes. Cultures were transferred to fresh media every 4 wks unless otherwise stated.

Statistics : Each treatment had 8 replicates and the LSD values at $\mathrm{p}=0.005$ obtained by analysis of variance for each time period to compare the means are given in the figures. For shoot tip explants standard errors of the mean are given with the means in tables.

\section{RESULTS}

Mature explants harvested from field-grown plants could not be established in vitro due to high rates of contamination. The sterilization procedure with $\mathrm{NaOCl}$ could not be extended more than 15 min or more than $10 \%$ due to heavy phenolic browning of the shoots in culture. Glasshouse-grown shoot materials on the other hand showed less phenolic browning compared to field grown materials but the degree of browning was sufficiently high to kill the explants. Sterilization with $0.2 \% \mathrm{HgCl}_{2}$, while disinfecting the shoots satisfactorily controlled the browning of the shoots to a considerable extent. Therefore, only glasshousegrown materials were used for the experiments reported here.

\section{Axillary shoot production potential of juvenile explanțs}

Results obtained from embryo cultured shoot tip explants are given in Table 1. Embryo cultured shoot tips contained only two axillary buds, located just below the shoot apex. Irrespective of the medium composition, the axillary buds emerged out and remained less than $2 \mathrm{~mm}$ in size. However, shoots grown on the control medium showed the best leaf growth and maintained as well on both S- 0 and S-1 media while defoliation was observed in cultures on S-2 and S-3 media. The shoot tips turned yellow on S-3 medium. Plantlets could be obtained within 
8 wks of culture on control medium, with no shoot proliferation. It was possible to maintain the cultures as shoot tips on both S-1 and S-2 media, but those on S-3 medium could not be maintained beyond 16 weeks; they turned yellow and eventually died.

Table 1: Percentage axillary bud break, mean length ( \pm sem) of axillary shoots and leaf growth on shoot tip explants derived from seed embryos.

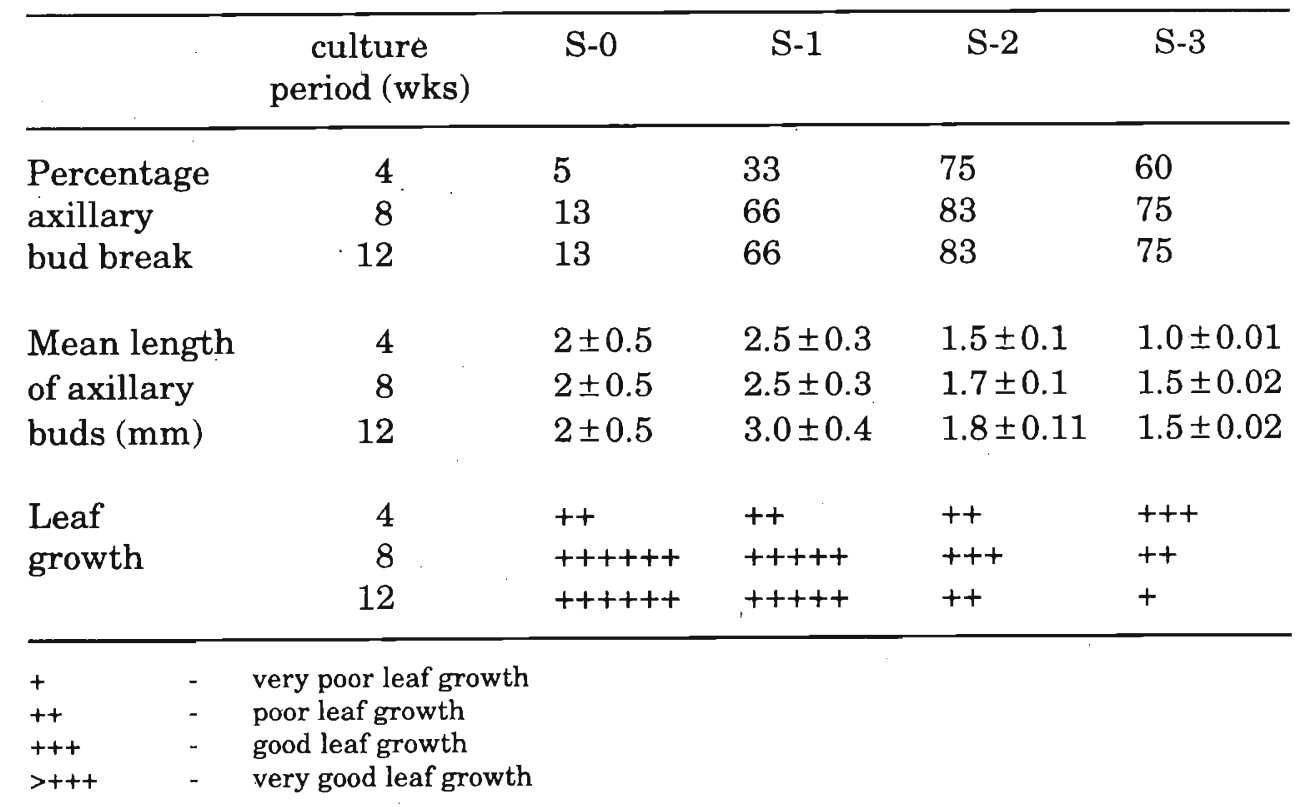

Results obtained for shoot tips of glasshouse grown seedling plants are given in Table 2. The length of the axillary buds produced remained less than $3 \mathrm{~mm}$ in all four media during the experimental period. Leaf growth of the cultures on different media was very similar to those of embryo cultured plants. Shoots on S-3 medium turned yellow. About 75 per cent of the shoot tips on S-0 medium and 15 per cent of them on S-1 medium produced roots. No shoot proliferation was observed throughout the experiment.

The axillary bud growth of shoot tips and nodal explants of juvenile origin are shown in Figure 1. Both shoot tips and nodes were 4-5 cm long, when cultured. S-1 hormones were used and there were 10 replicates from each type. Cultures were transferred to fresh media every 4 weeks. After 4 weeks, nodes were cut into pieces, each containing only 1-2 axils. Axillary shoots produced were subdivided into propagules, each was either a node approximately $5-10 \mathrm{~mm}$ long with at least one axil, or a shoot tip. The axillary bud elongation of nodal explants on four media are shown in Figures $2 \& 3$. 
Table 2: Percentage axillary bud break, mean length ( \pm sem) of axillary shoots and leaf growth on shoot tip explants derived from rootstocks. Leaf growth assessment as for Table 1.

\begin{tabular}{lcllll}
\hline & $\begin{array}{c}\text { culture } \\
\text { period (wks) }\end{array}$ & S-0 & S-1 & S-2 & S-3 \\
\hline $\begin{array}{l}\text { Percentage } \\
\text { axillary }\end{array}$ & 4 & 8 & 22 & 37 & 55 \\
bud break & 8 & 50 & 54 & 42 & 60 \\
& 12 & 50 & 54 & 46 & 65 \\
Mean length & 4 & $1.0 \pm 0.01$ & $2.0 \pm 0.5$ & $1.1 \pm 0.3$ & $1.0 \pm 0.2$ \\
of axillary & 8 & $1.7 \pm 0.1$ & $2.9 \pm 0.7$ & $2.0 \pm 0.1$ & $2.5 \pm 0.4$ \\
buds (mm) & 12 & $1.8 \pm 0.1$ & $2.9 \pm 0.7$ & $3.0 \pm 0.2$ & $2.5 \pm 0.4$ \\
Leaf & 4 & ++ & ++ & & ++ \\
growth & 8 & ++ & +++++ & + & ++ \\
& 12 & +++ & +++++ & + & 0 \\
\hline
\end{tabular}
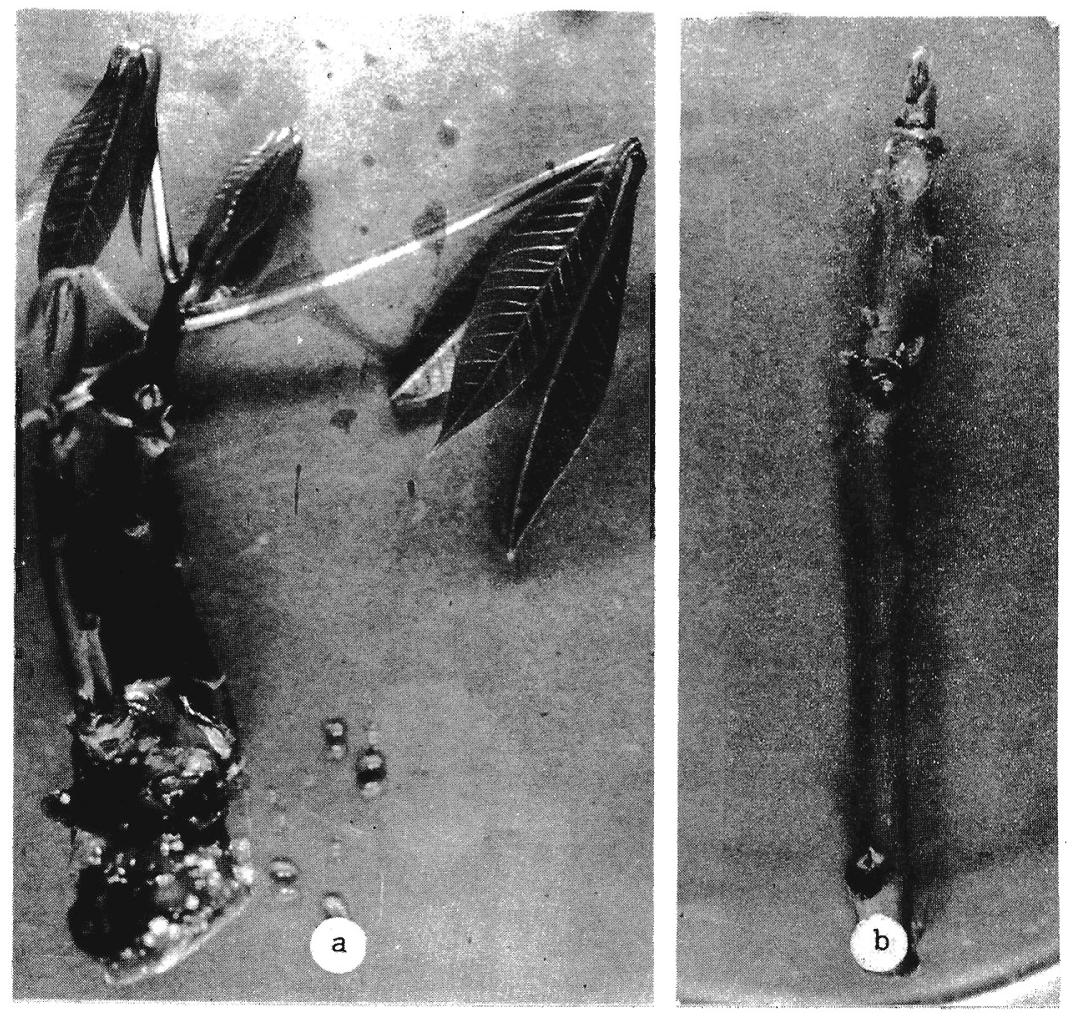

Figure 1.: Axillary shoots grown on rootstock derived (a) nodes (b) shoot tips Results after 8 weeks. 


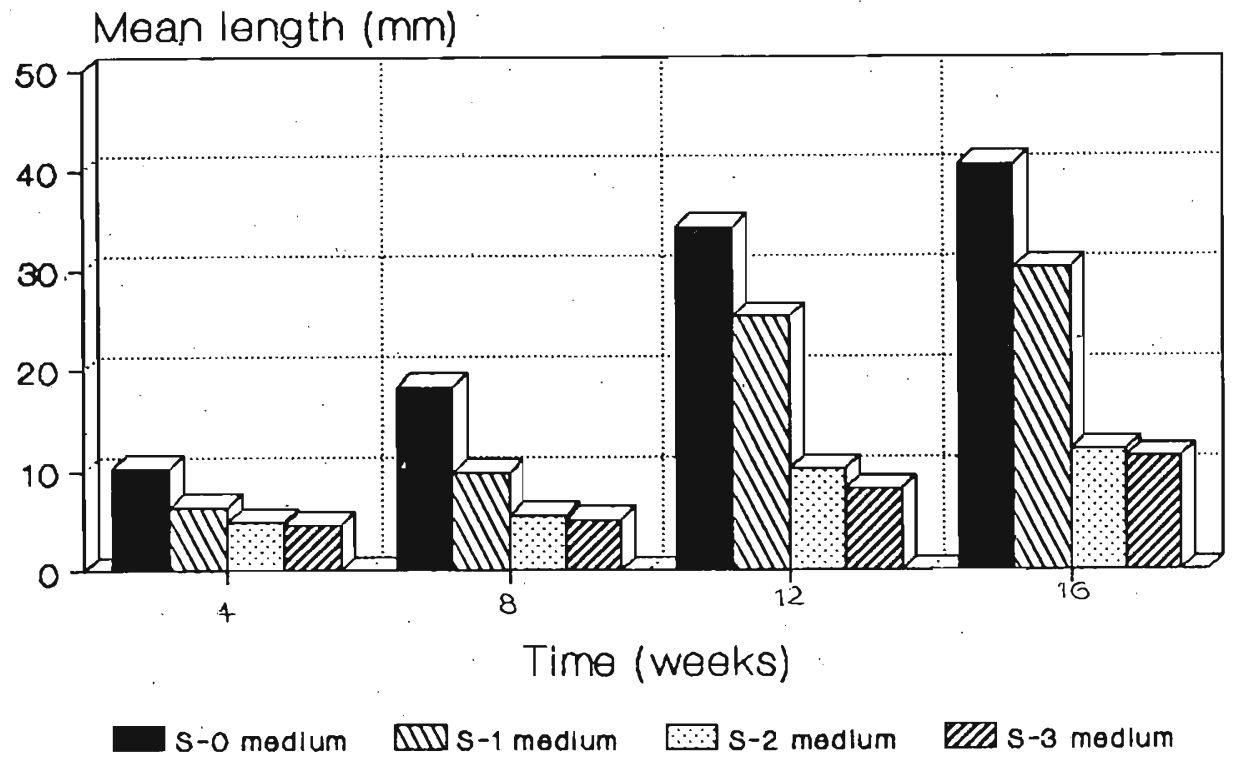

Figure 2 : Mean length of axillary shoots of nodal explants on four combinations of kinetin and BAP.
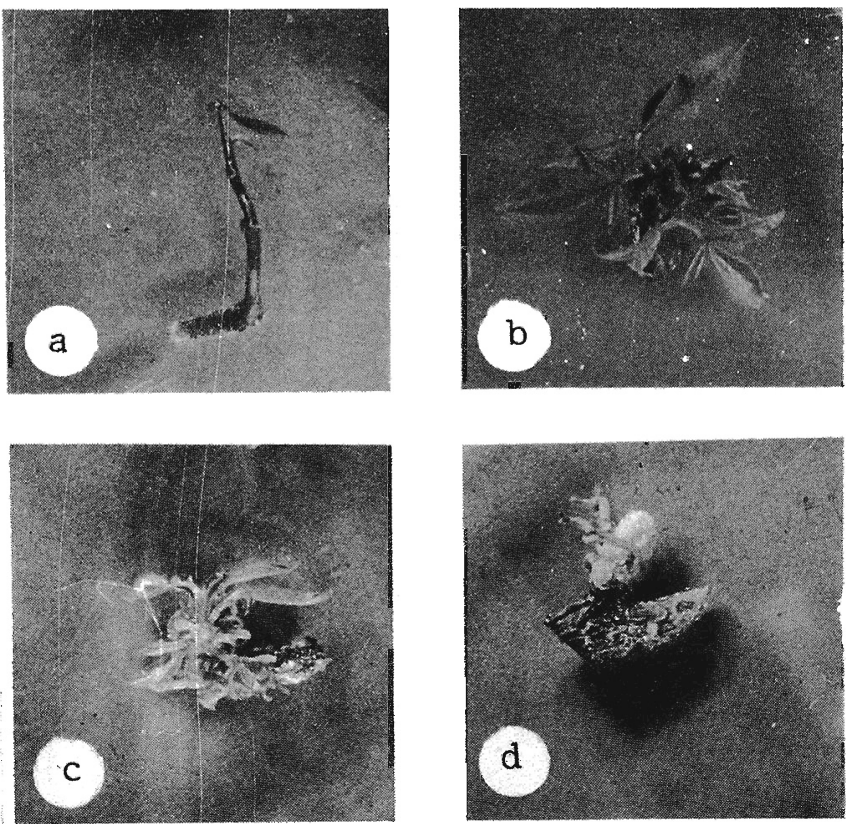

Figure 3 : Axillary shoot growth on four combinations of kinetin and BAP (a) S-O medium (b) S-1 medium (c) S-2 medium and (d) S-3 medium. 
The mean length of axillary shoots produced on control medium was the highest until they were cut into nodes to produce secondary axillary shoots. The leaf growth of axillary shoots on control medium was poor though the stems were dark green and healthy. Internodal expansion of the axillary shoots on S-1 medium was also satisfactory and a good leaf growth with normal leaves was observed throughout the experiment. The internodal expansion of the axillary shoots produced on S-2 and S-3 media was much smaller than, that observed on the control and S-1 medium (Fig. 3). Leaves produced on S-2 medium were "needle like" and pale green. This effect was more pronounced on S-3 medium. Root formation was observed on both primary and secondary nodes grown on control medium occasionally. At the end of 16 wks elongated axillary shoots were cut into pieces. The secondary axillary buds were observed only when the media contained exogenous hormones: From the 3 combinations, S- 1 medium showed the best growth. The secondary axillary shoots were separated into 1-2 nodes depending on the length of the shoot. These secondary nodes produced axillary shoots but they were very small. S-2 \& S-3 hormones were found to be too strong for these explants.
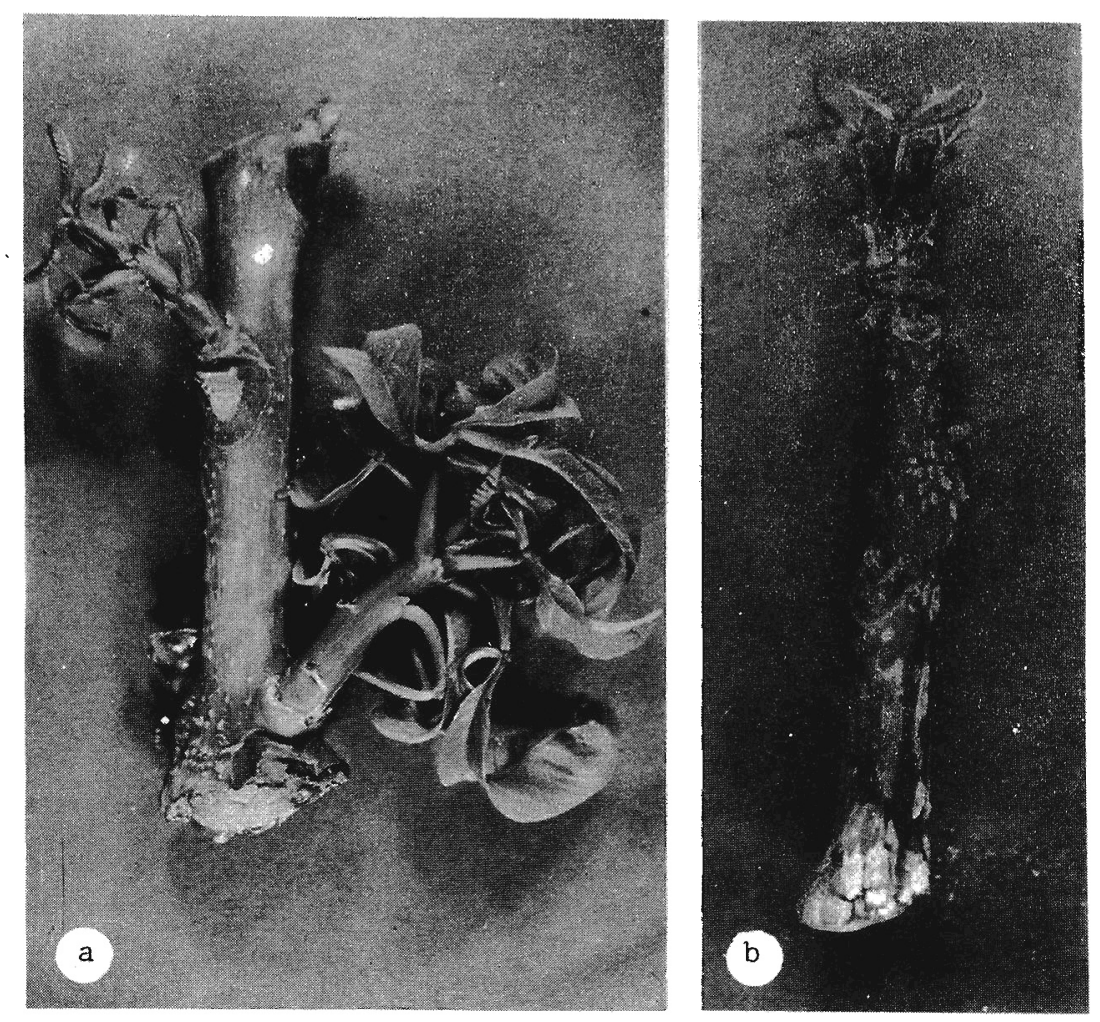

Figure 4: Axillary shoot growth on mature origin (a) nodes (b) shoot tips. 


\section{Axillary shoot production potential of mature explants}

As shown in Figure 4, the axillary bud break of shoot tip and nodal explants was similar to that of juvenile explants. The mean length of axillary shoots produced by nodal explants on four media are shown in Figure 5. The maximum axillary shoot elongation was observed in S-2 medium. Those produced on S-3 medium had small internodal lengths. Control medium showed the poorest axillary shoot growth and S-1 medium showed intermediate elongation. Leaf growth was also the highest on S-2 medium; leaves produced on S-3 medium were pale green and small. Axillary shoots on S-0 medium had no leaves and there were some leaves on those on S-1 medium. The primary axillary shoots grown only on S-1 medium were long enough to cut into pieces in order to enhance the secondary axillary bud growth. But the growth of the secondary axillary buds was not satisfactory compared to those produced by juvenile explants. Secondary axillary buds of about $2 \mathrm{~mm}$ size were observed with no elongation. The growth could not be maintained more than 8-12 weeks and cultures turned brown and died. Single plants could be produced by mature shoot tips, but the success rate was lower compared to juvenile materials. No sustainable growth was observed with either shoot tips or nodal explants to proliferate cultures.

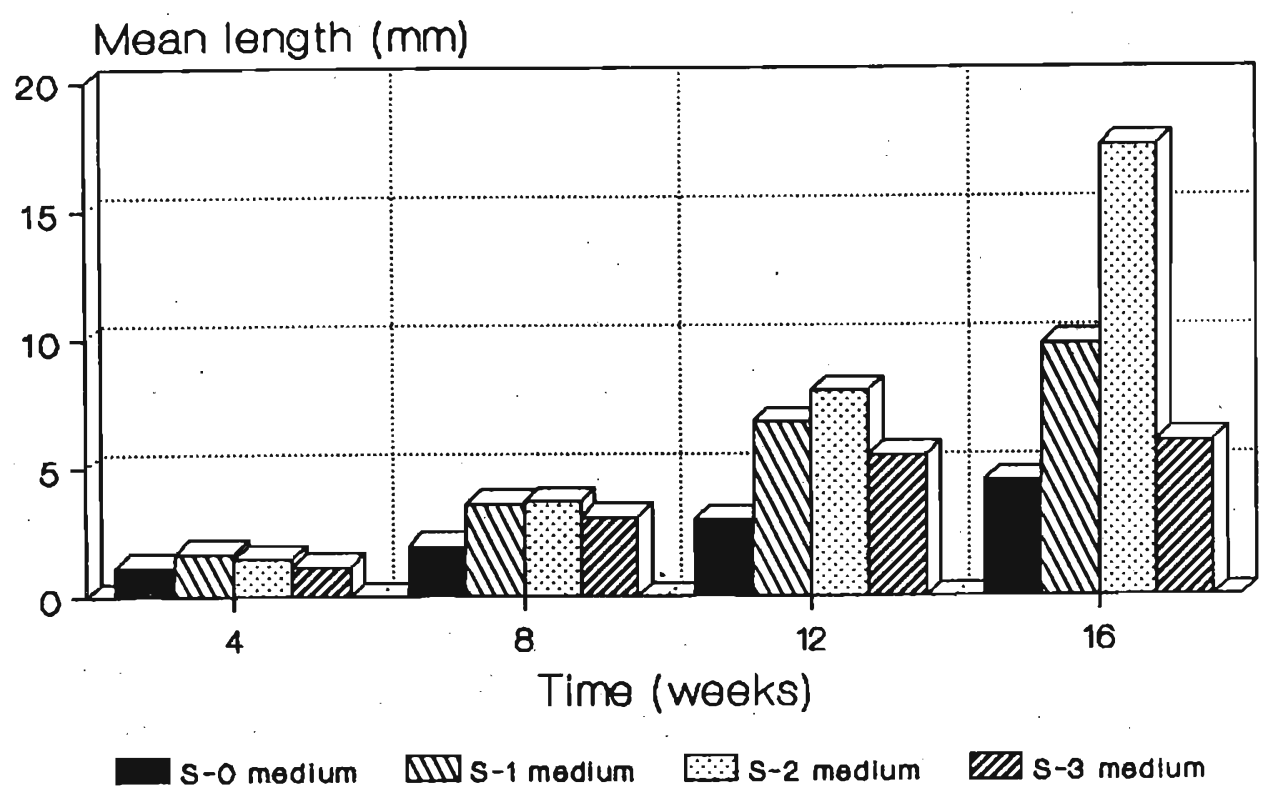

Figure 5: The mean lengths of axillary shoots produced by nodal explants on four media. 


\section{DISCUSSION}

The results obtained for shoot tips of both juvenile and mature explants were similar with respect to growth or elongation of axillary buds. Although this behavior of shoot tips has not been mentioned by those who worked only with nodal explants of Hevea, it is supported by the fact that there are no reports so far on the successful propagation of Hevea by shoot tip culture. Though there are reports on shoot tip culture to propagate juvenile Hevea, ${ }^{9}$ after a period of culture establishment, proliferation was achieved here by culturing sections of axillary shoots after the first sub culture.

The presence of exogenous hormones and their concentrations affected the number of axillary buds produced on shoot tips, but not their elongation. Hormone free medium had the lowest percentage of axillary bud break, but the total of $3 \mathrm{mg} / \mathrm{l}$ cytokinin in the medium was as good as $15 \mathrm{mg} / \mathrm{l}$. In fact, less cytokinin containing media favoured better maintenance of the shoot tips and good leaf growth.

Axillary bud break has been observed in shoot tip explants by using very low and also different combinations of growth regulators ${ }^{8-11}$ but the different type of explant does not permit a direct comparison.

In the present study, shoot tips harvested from both in vitro grown embryo cultured plants and in vivo grown seedlings gave similar results. One difference between the two types of shoot tips was the number of axillary buds on them. Embryo cultured shoot tips contained only two axillary buds while in vivo grown seedling shoot tips contained about ten or more buds. However, the axillary bud' proliferation was not successful with either type of shoot tips and therefore the higher number of axillary buds on in vivo grown shoot tips had no advantage. The advantage of using shoot tips instead of nodes, for axillary shoot proliferation, was the higher number of axillary buds present in shoot tips as compared to a node of the same length. Further, the shoot tip contained the most active part of the shoot including the apical meristem.

This behaviour of shoot tips and nodes could be due to the strong apical dominance present in the apex. When an apex of about $10 \mathrm{~mm}$ size, was removed from a shoot tip, the very first axillary bud of the resulting node started to grow suppressing the growth of axillary buds below that. However, it has been reported that shoot tips of seedling jackfruit were superior ${ }^{12}$ to nodal explants for shoot proliferation.

Apart from the similarity seen in the shoot tips of juvenile and mature origin Hevea, the behaviour of nodal explants was totally different. Due to high rate of contaminations and heavy content of phenolics, the culture establishment was very difficult with mature materials (data not presented).Field-grown materials could not be used due to these two problems and glasshouse-grown shoots contained the microbial flora and phenolic compounds in much less quantities. However, these two problems were further controlled by substituting $\mathrm{HgCl}_{2}$ for $\mathrm{NaOCl}$ and incorporating PVP in the culture medium. ${ }^{10}$ 
But the main problem of unsatisfactory growth of mature Hevea materials remained unsolved. The growth rate and the response to exogenous hormones of mature materials were very low compared to juvenile materials. This phenomenon has frequently been observed with shoot materials of woody perennial trees. Whether this mature phase could be changed into a juvenile phase by manipulating the medium composition, growth hormones and /or culture environment, remains to be determined.

Despite the maturity problem, manipulation of mature trees by in vitro techniques and establishing field trials with micropropagated material has been successful for other tree species including Eucalyptus ${ }^{13}$ Sequoia sempervirens, Pinus pinaster and Pinus radiata.${ }^{1}$ But, no shoot multiplication has so far been reported for mature materials of Hevea though, there are reports on axillary bud elongation ${ }^{8,10,11}$ and rooting of shoot tip explants. ${ }^{15}$

For some other plants, micropropagation of explants from mature trees, may require a cultural regime that is considerably different from that required by juvenile explants. Even if the explants from the mature trees were obtained from material collected from the best position of the tree and at the best time, to provide cells as juvenile as possible, these cells are often not as organogenetically competent as those of juvenile origin. Most trees have zones that retain a degree of juvenility longer than other areas of the tree. ${ }^{16}$ Roots often retain juvenility, and thus a capacity for vegetative propagation and juvenile type of growth, for a long time. ${ }^{17}$ Harvesting shoots close to the root system did not improve the growth in culture of mature Hevea (data not presented). Although mature meristems are considered to be more stable, both in vitro and in vivo, their phase related characteristics had been changed as a result of in vitro culture. ${ }^{14,18}$

Multiple grafting of scions from the selected mature trees onto seedling root stocks has been used effectively in some conifers. ${ }^{19,20}$ Once the graft is successful and the scion has grown, the tip of the new shoot is grafted onto another seedling. This procedure is repeated until the scion exhibits juvenile characteristics or responds like a juvenile plant. Transmission of rooting ability, which is a juvenile characteristic from seedling to adult Hevea brasiliensis has been demonstrated using this successive grafting technique ${ }^{21}$ Other rejuvenating techniques such as, application of synthetic plant growth regulators $\mathrm{s}^{22}$ and severe pruning ${ }^{23}$ were not effective to rejuvenate mature materials of Hevea (data not presented). However, it is evident that the rejuvenation is a prerequisite for possible cloning of adult trees. ${ }^{1}$ Experiments on successive grafting of Hevea are therefore now being carried out.

\section{References}

1. Pierik R.L.M. (1990). Rejuvenation and micropropagation. In: Current Plant Science and Biotechnology in Agriculture-Progress in Plant Cellular and Molecular Biology. pp. 91-101. Kluwer Academic, Netherlands. 
2. Songquan L., Xiehui Y., Xiang H. \& Laiyu X. (1990). Development phase change of Hevea brasiliensis and application of juvenile type clone. In: Proceedings of IRRDB Symposium on Breeding of Hevea brasiliensis. pp. 26-41. Kunming, China.

3. Bonga J.M. (1980). Studies in the vegetative growth and anatomy of the tea plant (Camellia thea Link) with special reference to the phloem. Annals of Botany 9(34): 183-216.

4. Hackett W.P. (1980). Control of phase change in woody plants. In: Control of Shoot Growth in Trees, Proceedings of Joint Workshop IUFRO Working parties on Xylem and Shoot Growth Physiology. pp. 257-272. Fredericton, Canada.

5. Durzan D.J. (1984). Special problems : adult vs juvenile explants. In: Handbook of Plant Cell Culture, Vol. 2 Crop Species. (Eds R. Sharp D.A. Amirato and Y. Yamada) pp. 471-503. Macmillan Publishing Co., London.

6. Chen C.H., Chen F.T., Chien C.F., Wang C.H., Chang S.C., Hus M.E., Ho Y.T. \& Lu T.M. (1979). A process of obtaining pollen plantlets of Hevea brasiliensis Muell Arg. Scientia Sinica 22(1) : 81-90.

7. Chen Z. (1984). Rubber (Hevea). In: Handbook of Plant Cell Culture, Vol 2, Crop Species, (Eds. R. Sharp, D.A. Amirato and Y.Yamada) pp. 546-571. Macmillan, London.

8. Carron M.P., Enjarlic F., Lardet L. \& Deschamps A. (1989). Rubber (Hevea brasiliensis Muell Arg). In: Biotechnology in Agriculture and Forestry, Vol.5, Trees. (Ed. Y.P.S. Bajaj) pp. 222-245. Springer-Verlag, Hamburg.

9. Gunatillake I.D. \& Samaranayake C. (1989). Shoot tip culture as a method of micropropagation of Hevea. Journal of the Rubber Research Institute of Sri Lanka 68: 33-44.

10. Seneviratne P. (1991). Micropropagation of juvenile and mature Hevea brasiliensis. PhD Thesis. University of Bath,U.K.

11. Chandrakanthi P.H.A.P. (1991). Micropropagation of juvenile and mature Hevea brasiliensis. Msc Thesis. University of Peradeniya, Sri Lanka.

12. Rahaman M.A. \& Blake J. (1988). Factors affecting in vitro proliferation and rooting of shoots of jackfruit (Artocarpus heterophyllus Lam). Plant Cell Tissue and Organ Culture 13:179-187.

13. Boulay M. (1985). In: Proceedings of International Symposium on In Vitro Propagation of Forest Tree-Species. pp. 51-81. Advertizing Research Foundation, Bologna. 
14. Gupta P.K, Nadgir A.L., Mascarenhas A.F. \& Jagannathan V. (1980). Tissue culture of forest trees: clonal multiplication of Tectona grandis L. (Teak) by tissue culture. Plant Science Letters 17: 259-268.

15. Asokan M.P., Sobhana P., Sushamakumari S. \& Sethuraj M.R. (1988). Tissue culture propagation of rubber (Hevea brasiliensis) (Willd ex. Adr de Juss) Muell Arg Clone GT i (Gondang Tapen T.) Indian Journal of Natural Rubber Research 1(2): 10-12.

16. Romberger J.A. (1976). An appraisal of prospects for research on juvenility in woody perennials. Acta Horticulturae 56:301-317.

17. Nozeran R., Bancilhon L. \& Neville P. (1971). Intervention of internal correlations in the morphogenesis of higher plants. In: Advances in Morphogenesis. (Eds. M. Abercrombie,J. Brachetv and T.J. King) pp. 2-66, Academic Press, New York.

18. Webster C.A. \& Jones O.P. (1989). Micropropagation of the apple rootstock M.9: effect of sustained subculture on apparent rejuvenation in vitro. Journal of Horticultural Science 64(49): 421-428.

19. Cresswell R.D., Boulay M. \& Franclet A. (1982). Vegetative propagation of Eucalyptus. In: Tissue Culture in Forestry. (Eds. J.M. Bonga and D.J. Durzan) pp. 150-181, Martinus Nijhoff/Dr.W. Junk Publishers, Netherlands.

20. Zimmerman R.H. (1985). Application of tissue culture propagation to woody. plants. In: Tissue Culture in Forestry and Agriculture.(Basic Life Sciences. Vol.32). (Eds R.R.Henke, K.W.Hughes, M.J.Constantin and A. Hollaender) pp. 165-177, Plenum Press, New York.

21. Muzik T.J. \& Cruzado H.J. (1958). Transmission of juvenile rooting ability from seedlings to adults of Hevea brasiliensis. Nature 181: 1288.

22. HackettW.P.(1985). Juvenility, maturation and rejuvenation in woody plants. Horticultural Reviews 7: 109-155.

23. Libby W.J. \& Hood J.V. (1976). Juvenility in hedged radiata pine. Acta Horticulturae 56: 91-98. 